Article

\title{
Habitat Classification of Temperate Marine Macroalgal Communities Using Bathymetric LiDAR
}

\section{Richard Zavalas ${ }^{1}$, Daniel Ierodiaconou ${ }^{1}$, , David Ryan ${ }^{2}$, Alex Rattray ${ }^{1}$ and Jacquomo Monk ${ }^{1}$}

1 Faculty of Science, Engineering and Built Environment, School of Life \& Environmental Sciences, Deakin University, P.O. Box 423, Warrnambool 3280, Australia;

E-Mails: rz@deakin.edu.au (R.Z.); alex.rattray@deakin.edu.au (A.R.); jacquomo.monk@deakin.edu.au (J.M.)

2 Worley Parsons, 250 St Georges Terrace, Perth 6000, Australia;

E-Mail: david.ryan75@gmail.com

* Author to whom correspondence should be addressed; E-Mail: iero@deakin.edu.au;

Tel.: +61-355-633-224; Fax: +61-355-633-462.

Received: 11 November 2013; in revised form: 19 February 2014 / Accepted: 24 February 2014 / Published: 7 March 2014

\begin{abstract}
Here, we evaluated the potential of using bathymetric Light Detection and Ranging (LiDAR) to characterise shallow water $(<30 \mathrm{~m})$ benthic habitats of high energy subtidal coastal environments. Habitat classification, quantifying benthic substrata and macroalgal communities, was achieved in this study with the application of LiDAR and underwater video groundtruth data using automated classification techniques. Bathymetry and reflectance datasets were used to produce secondary terrain derivative surfaces (e.g., rugosity, aspect) that were assumed to influence benthic patterns observed. An automated decision tree classification approach using the Quick Unbiased Efficient Statistical Tree (QUEST) was applied to produce substrata, biological and canopy structure habitat maps of the study area. Error assessment indicated that habitat maps produced were primarily accurate $(>70 \%)$, with varying results for the classification of individual habitat classes; for instance, producer accuracy for mixed brown algae and sediment substrata, was $74 \%$ and $93 \%$, respectively. LiDAR was also successful for differentiating canopy structure of macroalgae communities (i.e., canopy structure classification), such as canopy forming kelp versus erect fine branching algae. In conclusion, habitat characterisation using bathymetric LiDAR provides a unique potential to collect baseline information about biological assemblages and, hence, potential reef connectivity over large areas beyond the range of direct observation. This research contributes a new perspective for assessing the
\end{abstract}


structure of subtidal coastal ecosystems, providing a novel tool for the research and management of such highly dynamic marine environments.

Keywords: LiDAR; subtidal macroalgae; coastal; habitat mapping; exposed coast; bathymetry; reflectance; groundtruth video

\section{Introduction}

Shallow marine environments are vulnerable to a range of anthropogenic threats, including nutrient inputs, invasive marine pests, fisheries over-exploitation, and climate change [1]. Hence, it is important to quantify, understand, and manage a representative suite of habitats in the coastal marine environment [2]. The production of benthic habitat maps using remotely-sensed information offers a practical means to define potential community distributions in the marine environment, and hence facilitate ecosystem scale management [3,4]. However, mapping the seafloor is difficult along coastal margins, particularly in areas exposed to high wave action and turbidity (termed "exposed coasts" from here onwards). Habitat classification of these environments presents significant obstacles including logistical access restricting data collection and fluctuating water clarity [5].

A number of techniques are used for the ecological habitat mapping of marine environments. For example, multibeam echosounders (MBES) accurately define potential seabed habitat [6-10]. Geophysical datasets derived from MBES provide morphometric base layers, which may be supplemented with underwater observation data to "ground truth" inferred seabed habitats, providing a basis for supervised classification techniques [11]. However, MBES has several limitations when used in coastal marine habitats. For instance, MBES inherently loses efficiency in shallow water, with the ensonified area declining as water depth decreases [12]. Furthermore, nearshore areas are not always accessible for vessel-based sonar surveys because of heavy wave action and potential hazards (i.e., reefs) that have been poorly delineated [13]. These obstacles often result in an area of no information, termed "the white stripe," between sonar coverage and the coastline. Hence, approaches to fill these knowledge gaps are required, particularly because of the proximity of coastal environments to anthropogenic disturbances and other potential threats.

Airborne sensors have recently emerged as a cost-efficient option for surveys involving high resolution mapping of shallow water areas [14]. The invention of dual frequency Light Detection and Ranging (LiDAR) equipment has facilitated the use of aerial mapping sensors for hydrographic applications [15]. As a result, the detailed bathymetric data generated by LiDAR now provides a practical approach towards investigating the relationships between biotic and geophysical factors across large extents of shallow marine areas [16]. With the development of bathymetric LiDAR a number of studies have combined benthic terrain analysis techniques with LiDAR-derived information. Examples of such studies include relating terrain rugosity or complexity with fish species richness and abundance [17,18], detecting bottom type variation in relation to seagrass distribution [5,19], and discriminating between coral reef and non-coral dominated habitats [20,21]. Surveys using LiDAR have great potential for "seamless" (i.e., consistent) mapping over large geographical extents, therefore it remains important to evaluate information assimilated by LiDAR to characterise different marine 
environments. The application of multiple LiDAR terrain derivatives to inform classifications beyond the local scale i.e., $<10$ 's of $\mathrm{km}^{2}$ represents a novel approach for sub-tidal marine habitat classification.

Plant communities in terrestrial environments are often characterised from the canopy structure of vegetation [22,23]. A similar approach may be used for macroalgae communities, as demonstrated in a previous study in southern Australia [24]. The macroalgal communities of southern Australia are dominated by large kelps such as Macrocystis pyrifera and Ecklonia radiata, which are habitat engineers and provide ecosystem resources often supporting the biological productivity of mid latitude (temperate) shallow reef systems [25]. Therefore, it is necessary to develop a method to obtain accurate spatial information about the distribution of macroalgae communities over large areas (>10's of $\mathrm{km}^{2}$ ), and hence characterise exposed coastal environments. Bathymetric LiDAR provides a potential to delineate habitat availability for macroalgal communities and establish baseline information for future comparison.

Habitat classifications provide critical information about the distribution of macroalgae assemblages and substrata types in shallow subtidal coastal habitats. The study evaluates bathymetric LiDAR for benthic habitat characterisation of exposed marine environments where other mapping techniques cannot be used due to logistical constraints. We use video observation data to confirm the potential of LiDAR to bridge the knowledge gap in habitat classification from the shoreline to navigable waters in exposed coastal environments. In addition, we investigate the ability of LiDAR to classify temperate marine macroalgal distributions based on canopy structure. By validating the utility of LiDAR to differentiate habitat and macroalgal canopy types in high energy marine systems, we demonstrate the potential versatility of this technique for use in other coastal environments around the world.

\section{Methods}

\subsection{Study Area}

The study area is located on the coast of western Victoria, Australia (Figure 1), and is typical of a southern Australian coastal environment, which is exposed to the full force of the Southern Ocean weather systems [26]. The study area extends approximately $1.5 \mathrm{~km}$ offshore, with water depths ranging from 0 to $32 \mathrm{~m}$ (relative to Australian Height Datum; AHD) and fluctuating turbidity typical of temperate coastal marine waters (i.e., 0 to 4 nephelometric turbidity units, NTU). This area is characterised by shorelines containing high energy sandy beaches and cliffs, with a moderate to steep depth gradient [26]. In this region, shallow subtidal reef habitats are interspersed by areas of biolocastic carbonates and quartz marine sediments [27]. Benthic assemblages are dominated by canopy forming macroalgae, such as Phyllospora comosa and Ecklonia radiata, with a diverse understorey of rhodophytes and sessile invertebrates, representing a range of dynamic and diverse biological communities [28]. This marine environment cannot be accessed for extensive inshore boat based surveys, thus preventing the classification of benthic habitats by acoustic techniques. Furthermore, it is not possible to characterise the habitats using passive remote sensing, such as multi-spectral imagery, because of issues with water depth and surface reflectance. 
Figure 1. Study area showing the coastal zone between Warrnambool and Port Fairy, western Victoria, Australia. Digital Elevation Model of hill-shaded LiDAR bathymetry with the tow video tracks overlaid. Zoomed extent shows bathymetric detail of the Hopkins Bank region.

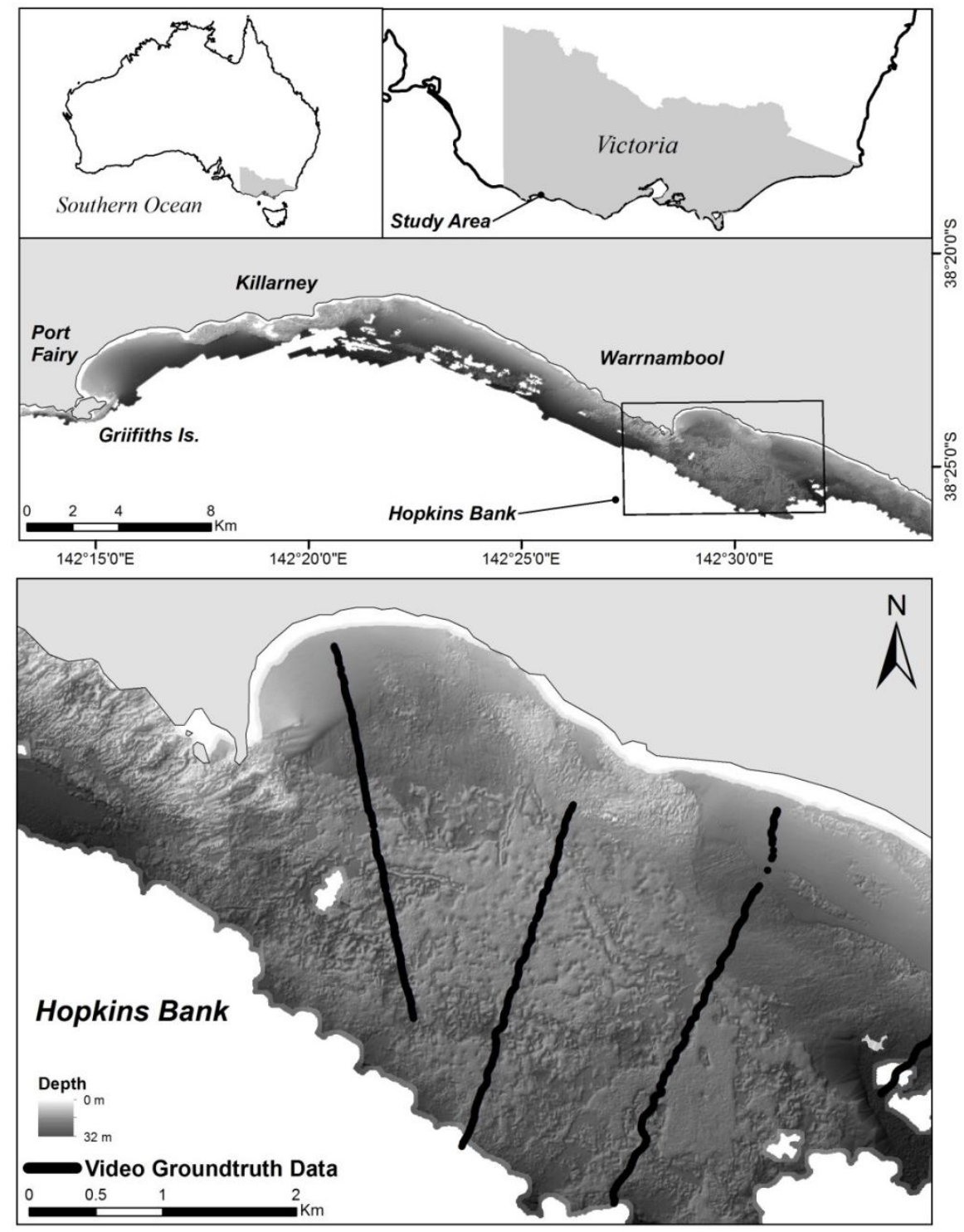

\subsection{Video Data Acquisition}

Eight ground truthing transects $(17 \mathrm{~km})$ were designed to maximise coverage across the known physical gradients of the study area, ranging from 3-32 m deep (Figure 1). Video data were collected in April 2010 using a VideoRay Remotely Operated Vehicle (ROV), retro fitted with a tow camera hydro-wing. The camera system was monitored and adjusted in real-time via an onboard ROV operator, maintaining the camera approximately $1 \mathrm{~m}$ above the seafloor, survey speed was generally between 1-2 knots. This enabled camera angle and altitude to record a consistent field of view maintaining spatial resolution for data classification. Video position on the seafloor was linked via a Tracklink Ultra Short Baseline system (USBL) to a differential GPS (Omnistar Satellite dGPS) and a $\mathrm{KVH}$ motion sensor (correcting for vessel pitch, roll and yaw). The cumulative contribution of each 
component resulted in a total propagated error (TPE) of $\pm 3.6 \mathrm{~m}$ for video seafloor position [29]. Track data logging was completed using Starfix suite 7.1, while a time stamp text overlay enabled video data to be co-located with track data.

\subsection{Video Data Processing}

Video ground truth data were examined to extract benthic biota and substrata characteristics of the seafloor. This information was extracted for each data record (representing 1 second of video) using the Victorian Towed Video Classification Program designed in Microsoft Access [30]. The recorded benthic characteristics included substrata type and percentage cover of dominant biota (Table 1), which were then used to aggregate the detailed video data into broad habitat classes (Table 1; Figure 2). Georeferenced point data records were imported into ArcGIS 9.3, and resampled into a grid that had the same resolution as LiDAR images $(5 \mathrm{~m})$ using a nearest neighbour approach.

Table 1. Class selection criteria of groundtruth video data for (a) substrata; (b) biological, and (c) canopy structure habitat classes, including density thresholds used to aggregate data. Reef (REEF), sediment (SED), mixed reef and sediment (REEF/SED), mixed brown algae (MB), mixed red algae (MR), mixed brown and red algae (MBMR), mixed seagrass (SG), no visible biota (NVB), canopy forming algae (CAN), fine-branching algae (FB).

\begin{tabular}{|c|c|c|c|c|c|c|c|c|c|}
\hline \multirow{2}{*}{\multicolumn{2}{|c|}{ Habitat Class }} & \multicolumn{7}{|c|}{$\%$ Cover } & \multirow[b]{2}{*}{$\begin{array}{l}\text { Groundtruth } \\
\text { Pixels (5 m) }\end{array}$} \\
\hline & & Reef & Sediment & $\begin{array}{l}\text { Brown } \\
\text { Algae }\end{array}$ & $\begin{array}{c}\text { Red } \\
\text { Algae }\end{array}$ & Seagrass & $\begin{array}{c}\text { Canopy } \\
\text { Algae } \\
\text { (i.e., Kelps) } \\
\end{array}$ & $\begin{array}{c}\text { Fine-Branching } \\
\text { Algae }\end{array}$ & \\
\hline \multirow{3}{*}{ (a) } & REEF & $\geq 75 \%$ & $\leq 25 \%$ & - & - & - & - & - & 992 \\
\hline & SED & $\leq 25 \%$ & $\geq 75 \%$ & - & - & - & - & - & 1416 \\
\hline & REEF/SED & $\geq 25 \%$ & $\geq 25 \%$ & - & - & - & - & - & 1716 \\
\hline \multirow{5}{*}{ (b) } & MB & - & - & $\geq 75 \%$ & $\leq 25 \%$ & Absent & - & - & 1192 \\
\hline & MR & - & - & $\leq 25 \%$ & $\geq 75 \%$ & Absent & - & - & 360 \\
\hline & MBMR & - & - & $\geq 25 \%$ & $\geq 25 \%$ & Absent & - & - & 1076 \\
\hline & SG & - & - & $\leq 25 \%$ & Absent & $\geq 25 \%$ & - & - & 76 \\
\hline & NVB & - & - & Absent & Absent & Absent & & & 1348 \\
\hline \multirow{3}{*}{ (c) } & CAN & - & - & - & - & - & $\geq 75 \%$ & $\leq 25 \%$ & 1324 \\
\hline & FB & - & - & - & - & - & $\leq 25 \%$ & $\geq 75 \%$ & 1224 \\
\hline & NVB & - & - & - & - & - & Absent & Absent & 1348 \\
\hline
\end{tabular}

\subsection{LiDAR Acquisition}

LiDAR depth and reflectance data were collected in April 2007 using a LADS Mk II system coupled with a GEC-Marconi FIN3110 inertial motion sensing system and a dual frequency kinematic geographic positioning system (kGPS), aboard a DeHavilland Dash-8 aircraft. LiDAR penetration into the water column was typically 2-3 times the Secchi depth [19]; this information was impaired in certain areas by high turbidity and breaking waves. The discrepancy in survey dates between groundtruth video and LiDAR was unavoidable in the current study as mapping surveys were originally conducted for the purpose of storm surge modelling the Victorian coastline and were only 
made available for habitat mapping post 2009. Groundtruth observations were completed in April corresponding with mapping surveys conducted in April three years earlier. This was done to limit the influence of seasonal variation in kelp biomass; as per seasonal variation observed in canopy forming macroalgae of southern Australia [31].

Figure 2. Still frames from ground truth video data, representing classified benthic habitats. (a) Sparse Ecklonia radiata and mixed red algae on high profile reef, classified as; reef (REEF), brown and red algae (MBMR) and fine-branching algae (FB); (b) Macrocystis pyrifera canopy on low profile reef, classified as; reef (REEF), brown algae (MB) and canopy forming algae (CAN); (c) Mixed Cystophora spp on high profile reef, classified as; reef (REEF), brown algae (MB) and fine-branching algae (FB); (d) Sparse seagrass bed on rippled sediments, classified as; sediment (SED) and seagrass (SG).

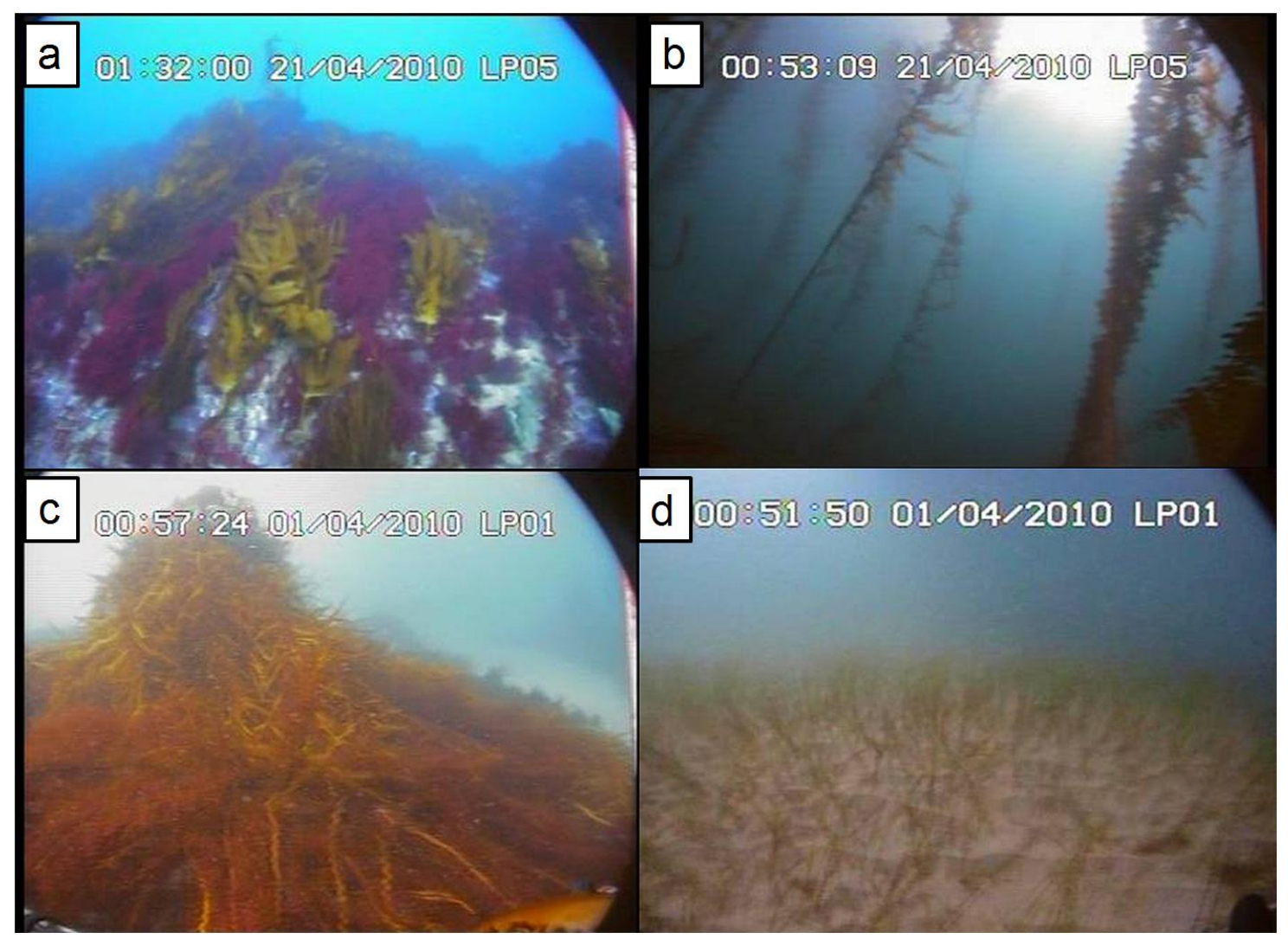

The survey flight was conducted from heights between 365 and $670 \mathrm{~m}$ at a ground speed of 175 knots. An Nd: Yag laser operating at $900 \mathrm{~Hz}$ on a stabilised platform, provided soundings with laser spot spacing set at $5 \times 5 \mathrm{~m}$ for appropriate data density. Flight lines for the mapping survey were spaced at approximately $220 \mathrm{~m}$, with a swath width of $240 \mathrm{~m}$, leaving an overlap of $10 \mathrm{~m}$. This amounted to a total of 19 flight lines across the study area. All depths were reduced to Australian Height Datum (AHD) as defined by observed tides connected to local survey marks. Vertical accuracy was determined by combining the errors due to the LADS Mk II system, tidal model, swell and water clarity. For horizontal accuracy the total expected error is a combination of the following errors; GPS errors, platform and laser positioning errors, position errors of detecting objects due to the distance 
between laser spots and sea surface errors. Vertical accuracy of the survey area is expected not to exceed $\pm 0.56 \mathrm{~m}$ (95\% confidence) and total expected horizontal error is $\pm 3.17 \mathrm{~m}$ (95\% confidence).

Reflectance data used was a measure of relative reflectivity of the seabed in a single wavelength (green/blue $532 \mathrm{~nm}$ ), calculated by determining the ratio between transmitted laser pulse energy and the compensated returned laser energy. The model used for producing Reflectance accounts for the following; laser energy transmitted on the pulse basis, beam incidence angles, water column attenuation, Aircraft Height and therefore losses in the air and energy loss at the water surface. The general equation used to calculate Reflectance is of the following form:

$$
\text { Reflectivity }=\frac{E_{r}(H+D)^{2}}{E_{l} e^{-2 C D} \cos \theta}
$$

Where $E_{r}=$ Received Energy, $E_{1}=$ Transmitted Energy, $H=$ Slant Height above sea surface, $\mathrm{D}=$ Slant Observed depth, $\mathrm{C}=$ Beam Attenuation Coefficient, $\theta=$ Angle of incidence at sea floor.

The above equation describes Raw Relative Reflectance that is subsequently normalized and logarithmically scaled to an 8-bit integer range 0-255. Because the dataset is of relative reflectance rather than an absolute value for each point, the entire dataset is scaled to ensure the full dynamic range is used over the dataset.

The bathymetry and reflectance values were processed to remove land (represented by values

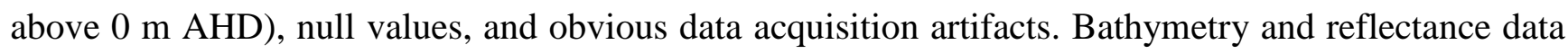
was processed using the following software; UNIX Generic Mapping Tools-UNIX MBSystem (processing/gridding), ERMapper (grid conversion, QC and 3D modelling) and ArcGIS (format conversions). Bathymetry and reflectance surfaces were gridded using the UNIX Generic Mapping Tools (GMT) application "near neighbor", using a search radius of 10\%. The nearest neighbor algorithm assigns an average value to each node that has one or more points within a radius centred on the node. The average value is computed as a weighted mean of the nearest point from each sector inside the search radius. The final output cell size was $5 \mathrm{~m}$.

\subsection{LiDAR Processing}

LiDAR data were used to produce a digital elevation model (DEM) of the study area $\left(57 \mathrm{~km}^{2}\right)$ at $5 \mathrm{~m}$ resolution. Bathymetry and reflectance datasets were used to create secondary terrain derivative surfaces (Table 2; Figure 3). The predictive capability of the LiDAR classification system may be increased by applying a multivariate approach that reflects proxies that potentially influence the distribution of biotic communities [5,32,33]. For example, bathymetric position index (BPI) defines the elevation of substratum in terms of troughs, flats, or peaks [34,35]. In comparison, maximum curvature describes the convex or concave surface of surrounding pixels [36], while aspect defines seabed orientation [37], which provides a proxy for exposure to wave action or seabed currents (Table 2; Figure 3). Rugosity [34,35] and slope [38] are considered strong potential surrogates for benthic biodiversity, through definition of seafloor structures such as sedimentation forms, which influence larval and spore settlement patterns and provide microhabitats for benthic assemblies [32]. The reflectance derivatives, Hue Saturation Intensity (HSI) [39] helps to separate encoding of surface scattering and topographic effects. In addition to bathymetry and reflectance, eight additional 
derivative datasets were produced using a range of processing techniques and applications in ENVI 4.7 and ArcGIS 9.3 software platforms (see Table 2).

Table 2. LiDAR bathymetry and reflectance derivative surfaces produced for habitat classifications.

\begin{tabular}{|c|c|c|c|}
\hline LiDAR Derivative & Description & Source & References \\
\hline $\begin{array}{c}\text { Bathymetric Position } \\
\text { Index (BPI) }\end{array}$ & $\begin{array}{c}\text { A measure of the relationship between the elevation } \\
\text { of a focal point compared to the elevation of the } \\
\text { surrounding terrain, defining peaks, flats, and } \\
\text { troughs. Both broad and fine scale BPI were } \\
\text { produced, by defining different sampling radii } \\
\text { (i.e., } 50 \mathrm{~m} \text { and } 15 \mathrm{~m} \text { ) }\end{array}$ & Bathymetry & {$[34,35]$} \\
\hline Maximum Curvature & $\begin{array}{l}\text { Describes the curvature of surrounding pixels. } \\
\text { Negative values indicate concave surfaces, while } \\
\text { positive values indicate convex surfaces. }\end{array}$ & Bathymetry & [36] \\
\hline Aspect & $\begin{array}{c}\text { Identifies the orientation of each pixel with values } \\
\text { between } 0 \text { and } 359 \text { degrees, using the value of the } \\
\text { steepest down-slope direction from each pixel to its } \\
\text { adjacent neighbours. }\end{array}$ & Bathymetry & [37] \\
\hline Slope & $\begin{array}{c}\text { The Slope function derivative denotes the maximum } \\
\text { rate of change between each pixel and its neighbours. } \\
\text { Slope values are defined by a tangent to a surface, } \\
\text { slope }=\arctan \left(\sqrt{\mathrm{d}^{2}+\mathrm{e}^{2}}\right) \text {, where }(\mathrm{d}) \text { and (e) are } \\
\text { coefficients of the quadratic equation representative } \\
\text { of the surface. }\end{array}$ & Bathymetry & [38] \\
\hline Rugosity & $\begin{array}{l}\text { A measure of surface roughness; values that are } \\
\text { closer to zero represent a smooth surface with low } \\
\text { rugosity, while high values indicate a rough surface. } \\
\text { Rugosity data is derived from the ratio between flat } \\
\text { surface area and the curved surface area of a defined } \\
\text { group of } 5 \text { m pixels. }\end{array}$ & Bathymetry & {$[34,35]$} \\
\hline Complexity & $\begin{array}{l}\text { Complexity is derived from the Slope derivative } \\
\text { product and is defined as a second derivative of } \\
\text { elevation, i.e., a measure of the slope of the slope. } \\
\text { The greater the variability in the slope between a } \\
\text { pixel and its adjacent neighbours, the higher the } \\
\text { surface complexity. }\end{array}$ & Bathymetry & {$[38]$} \\
\hline $\begin{array}{l}\text { Hue Saturation } \\
\text { Intensity (HSI) }\end{array}$ & $\begin{array}{l}\text { HSI was employed to separate surface scattering and } \\
\text { topographic influence, effectively reducing noise } \\
\text { levels within the reflectance dataset. HSI is a three } \\
\text { band (i.e., red, green, blue) synthetic color image, } \\
\text { separating areas of low and high frequency } \\
\text { reflectance by mapping them to Hue (dominant } \\
\text { colour wave-length of pixel) and Intensity (measure } \\
\text { of pixel brightness). Filter parameters: Hi-pass }=3 \text {; } \\
\text { Low-pass }=11 \text {. }\end{array}$ & Reflectance & [39] \\
\hline
\end{tabular}


Figure 3. LiDAR derivative surfaces produced for habitat classifications. Bathymetry derivatives: (a) complexity (i.e., slope of slope); (b) aspect; (c) Bathymetric Position Index (BPI); (d) rugosity; (e) maximum curvature; and (f) slope. Reflectance \& derivatives: (g) Relative Reflectance; (h) HSI-Green; and (i) HSI-Blue.

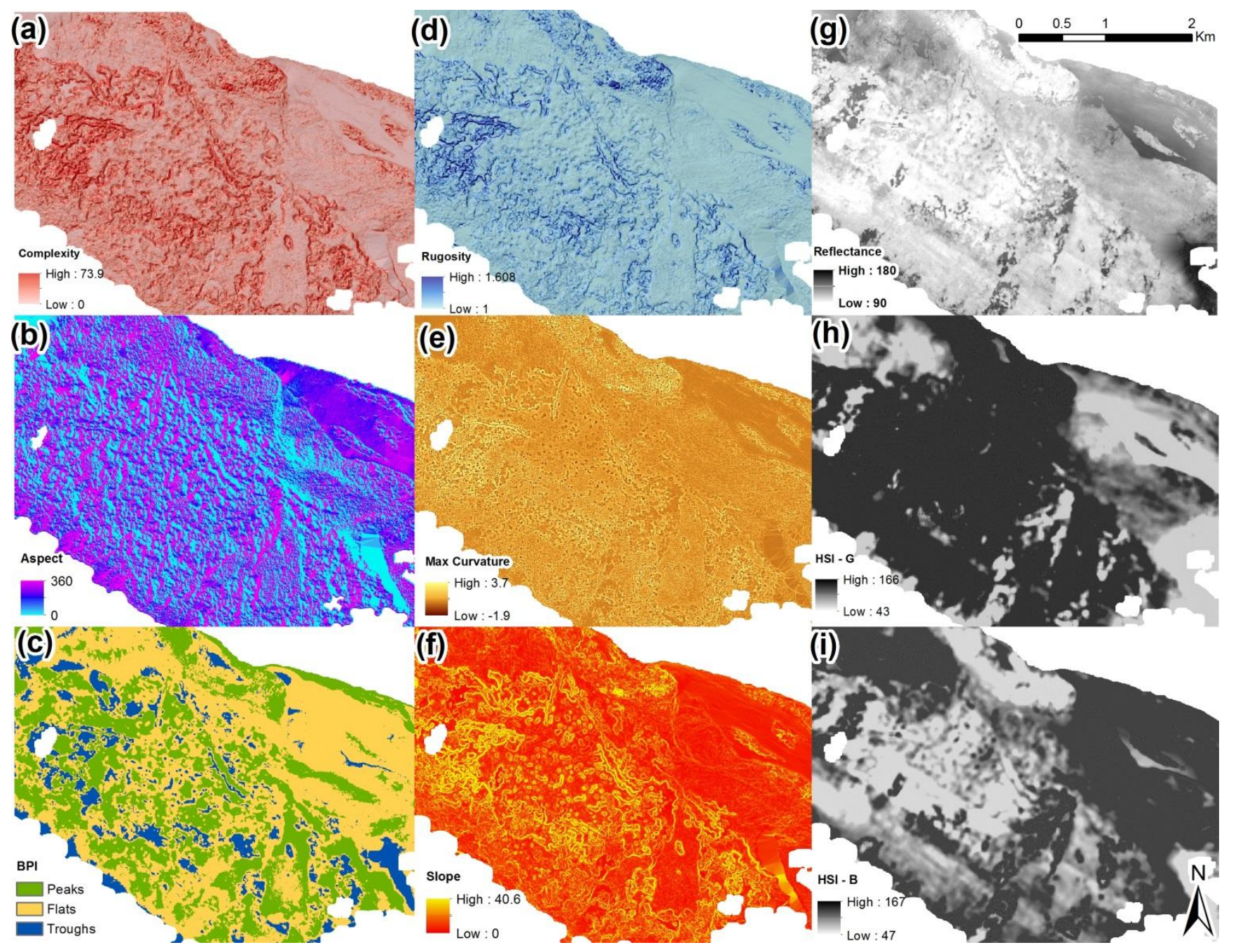

\subsection{Image Classification}

The Quick, Unbiased, Efficient Statistical Tree algorithm (QUEST) was used for the predictive classification of benthic habitats (Figure 4) [40]. The QUEST decision tree algorithm uses a series of binary decisions (nodes) to define rule based relationships between in situ video data and LiDAR derived predictor variables, implemented using the ENVI 4.7 RuleGen extension. The following parameters were used for QUEST to reduce over-fitting of classification trees, Minimum Node Size $=5$, Split Method $=$ Univariate, Variable Selection Method $=$ Unbiased, Alpha Value $=0.05$, Number of SEs for Pruning $=1$, Number of Folds $=10$. The QUEST classifier was selected instead of more traditional statistical methods such as maximum likelihood procedures due to certain advantages. Including, QUEST making no statistical assumptions, able to handle data represented on different measurement scales and non-exhaustive search routines, hence, avoiding overfitting the classification algorithm [41]. Predictor variables were tested for collinearity using Spearman's rho routine and variables returning correlation values $>0.8$ were omitted. Three classification maps were produced to 
assess the predictive capability of LiDAR to define different subtidal habitat types; namely, substrata type, biological structure, and canopy structure. The ground truth video data were organised according to the classification scheme levels, with each being subsequently used to inform the predictive modeling/image classification process (Table 2). Habitat classes for the substrata and biological classifications were defined using a standardised local-scale classification scheme described by Rattray et al. [9] and Ierodiaconou et al. [8]. The habitat classes for the canopy structure were defined from the canopy structure of algal assemblages, following a similar method to that used in the classification of macroalgae according to the Collaborative and Annotation Tools for Analysis of Marine Imagery and video (CATAMI) [42]. This approach was selected to investigate the efficacy of LiDAR for the predictive classification of macroalgal communities based on canopy structure alone.

Figure 4. Conceptual schematic showing the processing steps for the image classification of biological and geophysical habitat classes using a decision tree classifier.

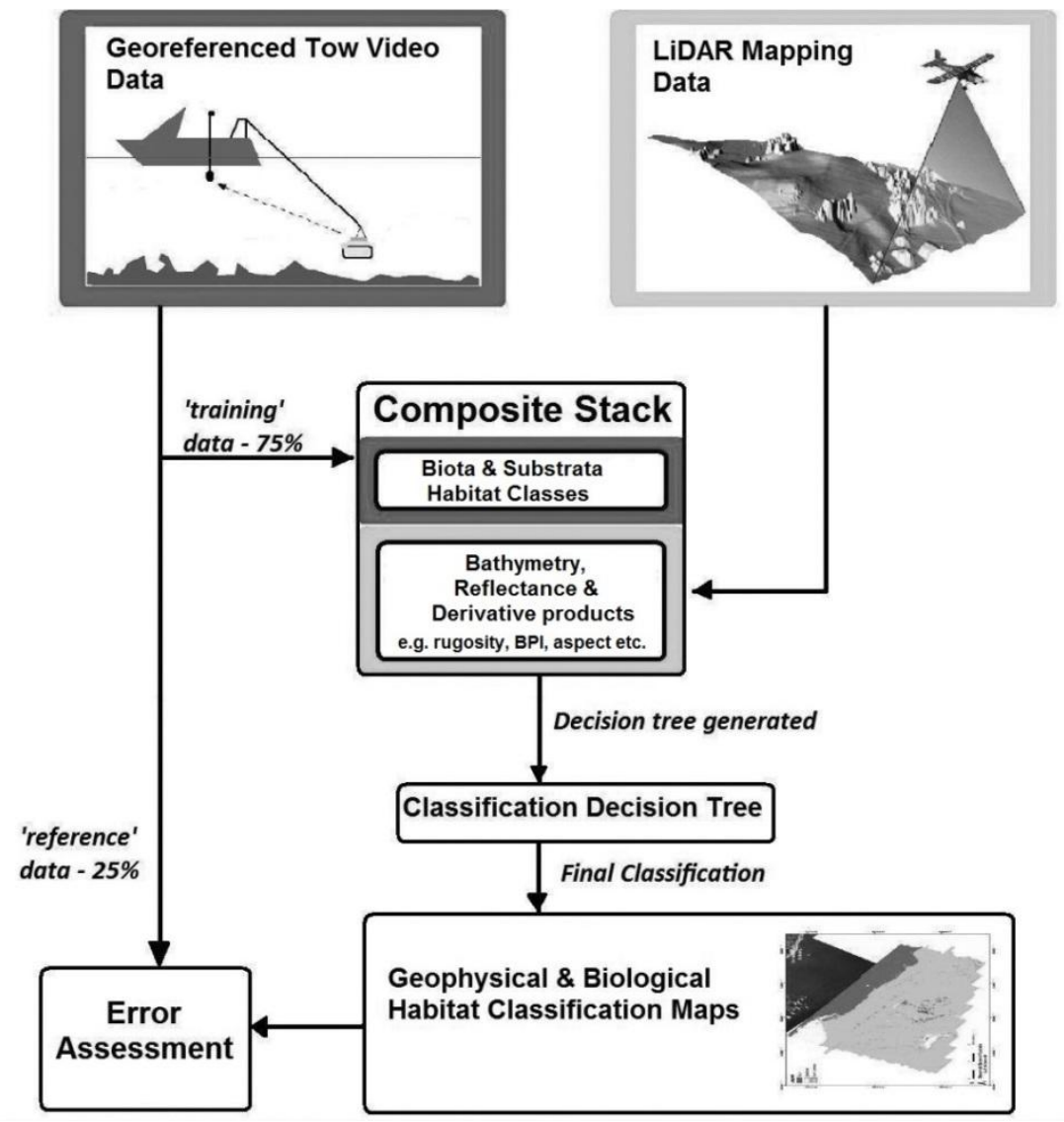

\subsection{Image Evaluation}

Before classification, the video ground truth data were randomly split into a training dataset (75\%) and a validation dataset for error assessment (25\%), after Franklin [43], error assessment data were excluded from the thematic classification process. Classification accuracy was assessed using standard error confusion matrices [44]. The error matrices permit the calculation of a suite of classified map accuracy measures for individual classes within biota and substrata classes [11].

The overall classification accuracy of a map is presented as a percentage, which is calculated by dividing the number of correctly classified error assessment pixels by the total number of error 
assessment pixels. Error matrices were used to calculate User's and Producer's accuracy, which provide percentage probability for the correct classification of individual habitat classes [45]. Accuracy percentages reported are corrected for bias by incorporating map marginal proportions [46]. In addition to accuracy percentages, the Tau coefficient (tau) was calculated, presenting a measure of the improvement of classification accuracy over a random assignment of map units to map classes [47].

\section{Results}

A total of 11 different habitat classes were defined across the three separate habitat classifications (Table 1; Figure 5). Both biological and substrata habitat classifications produced overall accuracies $\sim 70 \%$, with moderate agreement between classification and error assessment data. As expected, decision tree models that incorporated broader habitat classes had the best accuracies, while more complex habitat classifications resulted in reduced accuracy of some map classes.

\subsection{Substrata Classification}

The substrata classification was based on three broad geophysical categories; reef, bare sediment, and mixed reef/sediment. Classification for substrata was the most accurate of the three classifications produced with $74.8 \%$ overall accuracy and a tau of 0.623 , indicating overall moderate agreement between map classification and error assessment data (Table 3a; Figure 5a). The QUEST classifier produced a decision tree with 313 nodes (binary splits). The "reef" and "reef/sediment" classes had 23 decision tree layers and the "sediment" class had 17 tree layers.

The reef habitat was primarily characterised by medium profile reef with shallow fractures and overhanging ledges. The most distinct separation was obtained between the reef and sediment habitat classes (Table 3a), with the error assessment showing that reef habitats were incorrectly classified as sediment only $3.2 \%$ of the time, and no sediment pixels were incorrectly classified as reef (0\%). The error matrices indicated that the poorest accuracy occurred in the reef/sediment transition class. Hence, the reef/sediment class was equally misclassified as either reef (15.4\%) or sediment (15.4\%). This class was composed of both sediment dominated habitat with sporadic reef $(<25 \%$ coverage $)$ and reef with considerable sand inundation.

The "sediment" class contained unconsolidated sediments that occurred within exposed embayments and deeper regions of the study area. Sediment was the most accurately predicted class (92.6\%), which was probably because the highest percentage was held by this habitat type in the study area (Table 3a; Figure 5a).

\subsection{Biological Classification}

Biological habitat classification produced a map with an overall accuracy of $71.8 \%$ and a tau of 0.648 (Table 3b; Figure 5b). The QUEST classifier produced a decision tree with 377 nodes (binary splits). The "mixed brown algae" (MB) and "mixed brown/red algae" (MBMR) mapping classes had 20 tree layers, "mixed red algae" (MR) and "no visible biota" (NVB) classes had 16 tree layers, while the "seagrass" (SG) class had only 7 layers. "No visible biota" was the most accurate biota class (93.6\%). The "brown algae" class was dominated by phaeophytes, such as Ecklonia radiata, 
Sargassum spp, and Acrocarpia paniculata, and was the most accurate algae class (74.0\%). Brown macroalgae covered the largest area of any algae class $\left(16.5 \mathrm{~km}^{2}\right)$, representing $28.8 \%$ of the study area. Misclassification of "brown algae" was primarily due to confusion as "mixed brown and red algae" (Table 3b). The "mixed brown/red algae" class represented the transition in habitat between areas dominated by either "brown algae" or "red algae". However, the majority of error within the "red algae"class was caused by confusion with "no visible biota" (i.e., 24.4\% of MR misclassified as NVB). This is presumably due to red algae often observed in areas of sparse low profile reef interspersed with soft sediment patches, similar to the sediment dominated habitat often classified as "no visible biota".

Table 3. Error matrix for each classification comparing map class against groundtruth class. This table presents classified pixel numbers and users and producers accuracy for the individual habitat classes of each classification type: (a) substrata; (b) biological structure; and (c) canopy structure. Accuracy percentages are adjusted incorporating map marginal proportions. $\mathrm{T}_{\mathrm{e}}$ represents the tau coefficient.

(a)

\begin{tabular}{cccccc}
\hline Map Class & \multicolumn{5}{c}{ Error Assessment Class } \\
\hline REEF & REEF & REEF/SED & SED & Total & User's Accuracy \\
REEF/SED & $\underline{145}$ & 62 & 0 & 207 & $70.1 \%$ \\
SED & 85 & $\underline{284}$ & 40 & 419 & $67.8 \%$ \\
Total & 248 & 63 & $\underline{314}$ & 385 & $81.6 \%$ \\
Producer's & $61.1 \%$ & $62.2 \%$ & 354 & 1011 & \\
Accuracy & & & $92.6 \%$ & $\mathrm{~T}_{\mathrm{e}=0.623}$ & \\
\hline
\end{tabular}

(b)

\begin{tabular}{cccccccc}
\hline Map Class & \multicolumn{7}{c}{ Error Assessment Class } \\
\hline NVB & NVB & SG & MB & MBMR & MR & Total & User's Accuracy \\
SG & $\underline{308}$ & 19 & 16 & 17 & 22 & 382 & $80.6 \%$ \\
MB & 0 & $\underline{0}$ & 1 & 0 & 0 & 1 & $0 \%$ \\
MBMR & 13 & 0 & $\underline{222}$ & 94 & 17 & 346 & $64.2 \%$ \\
MR & 8 & 0 & 53 & $\underline{144}$ & 12 & 217 & $66.4 \%$ \\
Total & 337 & 19 & 298 & 269 & $\underline{39}$ & 67 & $58.2 \%$ \\
Producer's & $93.6 \%$ & $0 \%$ & $74.1 \%$ & $46.3 \%$ & $49.1 \%$ & $\mathrm{~T}_{\mathrm{e}=0.648}$ & \\
Accuracy & & 0 & 6 & 14 & & \\
\hline
\end{tabular}

(c)

\begin{tabular}{cccccc}
\hline Map Class & \multicolumn{5}{c}{ Error Assessment Class } \\
\hline NVB & NVB & CAN & FB & Total & User's Accuracy \\
CAN & $\underline{228}$ & 16 & 37 & 281 & $81.1 \%$ \\
FB & 105 & $\underline{261}$ & 63 & 332 & $78.6 \%$ \\
Total & 341 & 331 & $\underline{206}$ & 365 & $56.4 \%$ \\
Producer's & $73.3 \%$ & $77.2 \%$ & $64.8 \%$ & $\mathrm{~T}_{\mathrm{e}=0.580}$ & \\
Accuracy & & & & & \\
\hline
\end{tabular}


Figure 5. Habitat classifications of the study area, with the zoomed extent showing the distribution of habitat classes in the Hopkins Bank region. (a) Substrata type; (b) Biological structure; and (c) Canopy structure. Classified tow video tracks are overlaid.

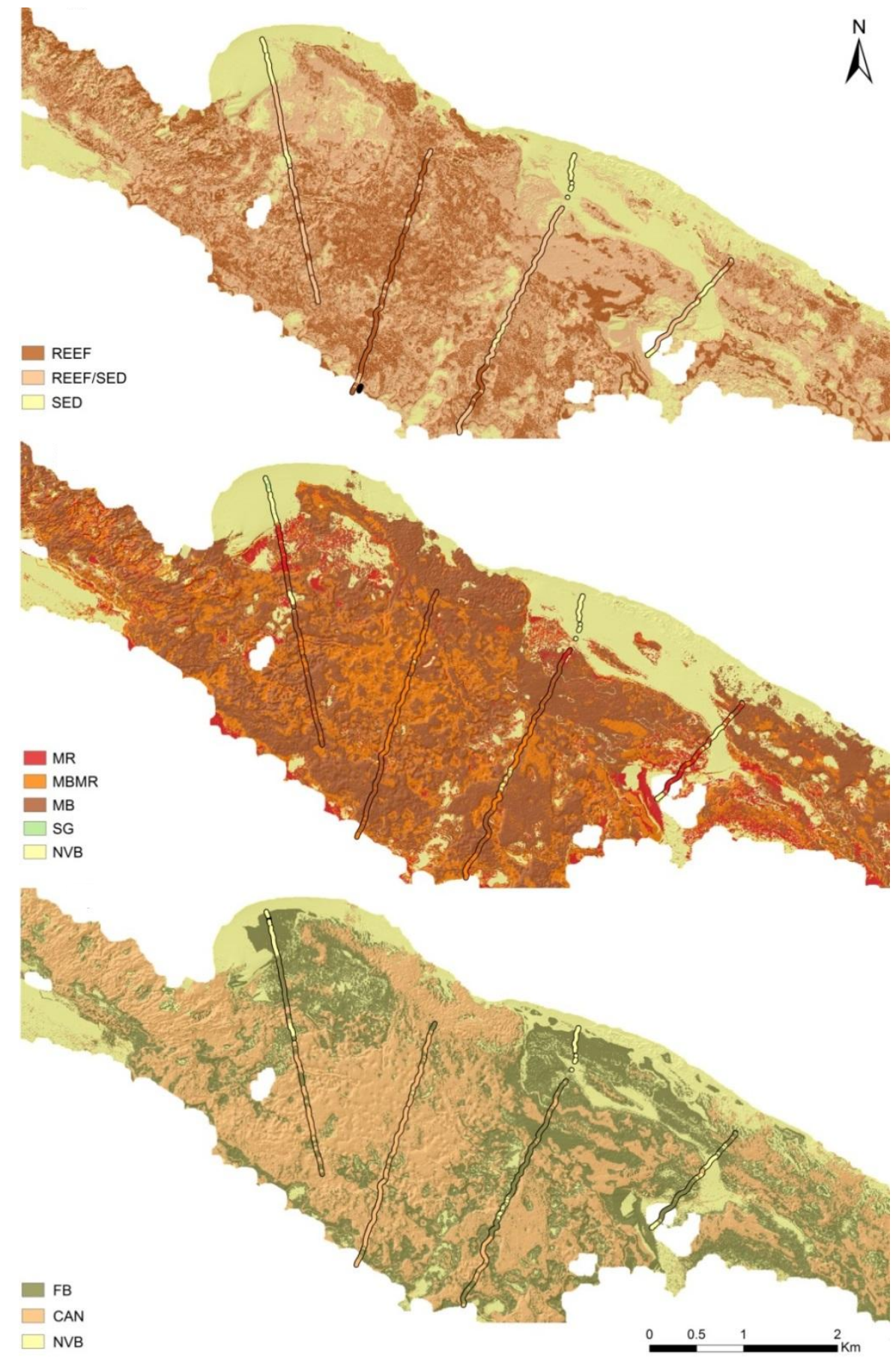

The "seagrass" habitat class covered an area of $0.025 \mathrm{~km}^{2}$. However, poor classification accuracy was achieved ( 0\%), as seagrass was typically classified as NVB (Table 3b). There were few groundtruth observations of seagrass for the training and evaluation of this habitat class (Table 1); consequently, seagrass contributed a negligible amount within the study area $(<0.1 \%$ coverage). This low presence was reflected by poor discrimination between bare sand and sparse seagrass habitat. Shoot density of seagrass beds is estimated to be $<1000$ shoots $/ \mathrm{m}^{2}$ in the study area. Blade-shaped seagrass beds at this density have been shown not to alter LiDAR bathymetry [48], therefore it is 
logical that habitat maps failed to accurately define the distribution of seagrass, given seagrass density and lack of groundtruth observations.

\subsection{Canopy Structure Classification}

The most accurate biological classification type was that using canopy structure, with a mapping accuracy of $72.0 \%$ and of tau of 0.58 , indicating moderate agreement between classification and error assessment data (Figure 5c). The QUEST classifier produced a decision tree with 197 nodes (binary splits). "Canopy macroalgae" (CAN) and "fine branching algae" (FB) had 17 tree layers, "no biota" had 14 decision tree layers. The most accurate classification was obtained for the "canopy macroalgae" (CAN) class (77.2\%), while the least accurate classification was obtained for the 'fine branching algae' (FB) class (64.7\%) (Table 3c; Figure 5c). The "no visible biota" class represented $35 \%$ of the study area coverage, primarily containing bare sediment habitats. Most of the error for the 'no visible biota' class was attributed to confusion with the 'fine branching algae' class (Table 3c). This assumption was confirmed by "no visible biota" being most commonly misclassified as "fine branching algae" (30.8\%), rather than "canopy macroalgae" $(2.4 \%)$. The "canopy macroalgae" class represented a mixture of large phaeophytes with dense vegetative canopy growth and long fronds $(>1 \mathrm{~m})$. This habitat class was dominated by the kelps Ecklonia radiata and Phyllospora comosa, and mainly occurred on higher profile subtidal reefs at high wave energy locations. Classification error in the "canopy macroalgae" class was also caused by confusion with "fine branching algae", rather than "no visible biota" (Table 3c). This result reinforces the observation that error between canopy structure classes was predominantly caused by confusion with the "fine branching algae" class, as "no visible biota" and "canopy macroalgae" were clearly differentiated. The "fine branching algae" class covered $35 \%$ of the study area, and algae was characterised by mixed tufting algal species with thallouse fronds of $<1 \mathrm{~m}$ in length (e.g., Plocamium sp. and Phacelocarpus peperocarpus). This habitat also contained sparsely distributed kelps (e.g., Ecklonia radiata and Macrocystis paniculata), and was typical of low to medium profile sand inundated reefs. These results indicate that much of the error associated with classification accuracy is attributed to confusion between habitat classes of similar physical characteristics, because of the lack of "abrupt" boundaries in the distribution of benthic habitat types.

\section{Discussion}

This study used video observations to validate LiDAR-derived seafloor characteristics in a spatially-explicit modeling approach to delineate benthic habitats. The use of LiDAR bathymetry and reflectance datasets provided good classification results with overall predictive accuracies exceeding $71 \%$. Furthermore, the prediction accuracy was also high for certain habitat classes, including sediment (93\%), mixed brown algae (74\%), and canopy algae (77\%) (Table 3). Discrepancies primarily occurred between classes that had similar physical habitat characteristics. Classification categories were grouped according to distinct habitat attributes; however, certain species and substratum traits inevitably overlapped across classes. For example, the results indicate that the misclassification of the "reef" and "sediment" classes was caused by the overlapping habitat class "reef/sediment". This misclassification was evident along the spatial boundaries of habitat classes, where "speckling" occurred (Figure 5). This issue was attributed to the lack of clearly delineated 
boundaries in the benthic distribution of actual seafloor habitats. Often, biological communities are not "neatly" defined with clear spatial boundaries, as species composition often changes gradually along environmental gradients [49]. Prediction error associated with these types of transitional zones between habitats has been previously observed for a range of classification techniques [9,50-52]. The predictive classification method adopted in this study presents bathymetric LiDAR as a viable mechanism for mapping macroalgal assemblages in exposed marine environments. However, error associated with misclassification between similar habitats illustrates the difficulty in defining clear decision rules to distinguish between different benthic habitats.

Benthic characterisation using LiDAR enables a knowledge gap to be filled regarding exposed coastal systems (of <25 m seabed depth). Surveying coastal environments is traditionally limited to areas where the access of acoustic systems is possible, or high water clarity when using aerial remote sensing techniques. Acoustic systems represent a widely used technique for the benthic characterisation of marine environments, producing high resolution habitat maps [6,7,53]. Nevertheless, a data gap arises adjacent to the shoreline, because vessel mounted MBES systems cannot enter shallow water environments [54,55]. In this study, LiDAR was specifically used to target the onshore-offshore transition zone $(0-30 \mathrm{~m})$, linking bathymetry information from shallow to deeper marine habitats in exposed coastal environments. The advantage of LiDAR is illustrated by its ability to target littoral habitats, capturing the shallow section of the ecological transition from macroalgae dominated habitats through to sessile invertebrate assemblages. A limiting factor is the cost of LiDAR surveys which are influenced by different components such as survey remoteness, scale and data density considerations. However, in comparison LiDAR efficiency still outweighs MBES while remaining able to detect comparable seafloor features and survey benthic habitat inaccessible to vessel based surveys [14]. Surveying littoral marine habitats provides the potential to integrate LiDAR and MBES classification systems. This could be further developed by combining data from the current study with the MBES habitat characterisation of the Hopkins Bank extending further offshore $(\sim 6.5 \mathrm{~km})$ from the study area [30]. Copeland et al. [55] demonstrated the difficulty of using MBES for benthic classification in the littoral zones of a closed marine embayment, suggesting bathymetric LiDAR as a suitable solution for the littoral gap. The validation of LiDAR methodology by the current study indicates the potential of obtaining full coverage of benthic habitat distribution in exposed coastal environments, making this approach highly unique. Therefore, it is worth further developing this technique for mapping the habitats of exposed coastal environments.

Spatial-dependence within groundtruth video transects and the possible influence of spatial autocorrelation remained a challenging issue for the current study. Tow video transects provide continuous coverage of seafloor habitat enabling efficient collection of in situ observation data and identification of transition zones in habitat types. However within transect groundtruth points have the potential for lack of spatial independence, resulting in possible inflation of predictive accuracy leading to false confidence in model capability [44,56]. It is acknowledged that the models presented in the current study may contain an unknown degree of spatial autocorrelation. However, accounting for spatial autocorrelation structure in community models is difficult and an ongoing issue [57,58]. Methods for assessing spatial autocorrelation in community classifications area generally restricted to continuous as opposed to categorical information such as different dominant habitat classes used in the current study. Foster et al. [57] propose using a Bayesian Markov model approach in order to account 
for spatial autocorrelation while retaining representation of within transect variability of groundtruth data. Accordingly, a key aspect of further work will be to revise sample design and/or statistical methods [57] to remove any possible source of spatial-dependence while retaining coverage efficiency in the groundtruth survey.

The active nature of the LiDAR sensor was able to generate good results in the relatively turbid and exposed coastal waters of southeastern Australia. Survey data was reliable to 25-30 m, approximately half the LiDAR penetration reported in some coral reef tropical marine environments [59]. Several studies have recently emerged that employ bathymetric LiDAR with ground truth observations to accurately classify different marine environments [5,33,60,61]. Specifically, Chust et al. [5] used LiDAR-derived bathymetric datasets in conjunction multi-spectral imagery and MBES to the delineate shallow-water habitats of the Oka estuary in Spain, with accurate results (between $84.5 \%$ and 92.1\% accuracy). Chust et al. [5] concluded that bathymetric LiDAR provides unique seafloor information obscured from MBES that improves habitat mapping reliability in the coastal fringe. Tulldahl et al. [62] accurately classified benthic habitats such as soft and hard substrate with vegetation to $10 \mathrm{~m}$ finding that accuracy was significantly increased using LiDAR, bathymetric derivatives and satellite data to inform classifiers. Other studies have also successfully characterised the physical substratum of sheltered coastal waters with the biological classification and habitat suitability modeling of various environments, including seagrass beds and saltmarshes $[33,63,64]$. The current study expands on this knowledge by successfully applying LiDAR for classification of temperate macroalgae in a dynamic marine environment exposed to high wave action and turbidity, previously considered "no data" areas for benthic habitat classification. This expands the range of known physical environments that we may characterise using active remote sensing techniques, revealing the potential to define the distribution of important macroalgae (e.g., kelps) at fines scales over large extents $\left(>100 \mathrm{~km}^{2}\right)$. In addition, this study extends on previously published literature by incorporating LiDAR reflectance data and other derivative surfaces to further inform the decision tree classifiers applied. This approach was selected to validate bathymetric LiDAR based on video observation data for its ultimate use as a standalone tool for habitat classification of exposed coast environments.

Different habitat classifications were assessed to investigate different macroalgae assemblages using LiDAR. The biological and canopy structure classifications represented different approaches to grouping macroalgae communities, the former was solely based on taxonomic groupings, while the latter was based on species structural compositions. In terrestrial systems, it is common to use the structure of plants to classify different habitats. For instance, LiDAR has been previously used to assess canopy height and the biomass of terrestrial forests [22], or to delineate different woodland classes, based on species composition and vegetation structure [23]. The composition of macroalgal communities obtained from the video ground truth data was used to define the habitat classes for the LiDAR canopy structure classification. Even though the two algae classes that were defined through this classification system contained similar species, they were assessed based on key differences in canopy structure and species abundance. Conversely, for the biological classification, the "brown algae" class contained a range of habitats, including Macrocystis pyrifera kelp forests and dense E. radiata canopy growth, in addition to lower profile Sargassum spp. Although these habitats represent different distinct macroalgal assemblies, in the biological classification they were classed as 
the same habitat; see examples Figure 2. Kelp dominated communities based on algal canopy structure were also delineated in a previous study in southern Australia. Toohey [24] observed that macroalgal communities dominated by $E$. radiata were significantly different to topographically simple and complex reefs, and suggested that they should be considered as two distinct habitats. Topography was not seen as a single factor driving differences in algae assemblages; rather, it was used to label a collection of co-varying factors that alter key biological processes [24]. For instance, high sediment loads on low profile reef can reduce benthic recruitment via burial or scour effects $[24,65]$. In contrast, increased water motion and light attenuation on higher profile reef reduces interspecific competition for light, leading to greater understorey species richness and vegetative growth [24]. The combined effect of these factors indicates that these algal communities should be categorised as different habitats. The current study validated the effectiveness of LiDAR at delineating macroalgae communities by comparing it against: (1) maps derived from canopy structure classification; and (2) maps derived from taxonomic classification.

\section{Conclusions}

This study validated LiDAR for the effective benthic classification of macroalgae communities in a highly dynamic and exposed coastal environment. Traditionally, biological communities in exposed marine environments have been difficult to survey; however, this technique presents an opportunity to characterise seafloor habitats over large extents at fine resolution. The habitat classifications produced by this study provided baseline information about the distribution of benthic assemblages across the study area, and demonstrated the capacity of LiDAR to define temperate macroalgal communities based on assemblage structure. This information could be applied to monitor habitats and to model natural and anthropogenic induced change to marine environments. Within the context of climate change, bathymetric LiDAR could provide valuable information for monitoring biological communities that are vulnerable to the impact of storm surges and global sea level rise [5]. The combination of LiDAR and established acoustic classification techniques provides an opportunity for the seamless characterisation of seabed habitats from the shoreline to deeper marine environments. The relatively cost efficient, continuous datasets produced from LiDAR, allow benthic habitat mapping to be conducted systematically over large areas. LiDAR provides a mechanism to quantify information about benthic assemblages for the habitat classification of the coastal fringe, representing a novel development for the environmental management of exposed coastal ecosystems.

\section{Acknowledgments}

The authors acknowledge the efforts of the Fugro LADS Pty. Ltd. survey team, who collected the LiDAR data. We thank the Governmental Department of Environment and Primary Industries for the provision of LiDAR datasets, initially collected for storm surge modeling, as part of the "Future Coasts Program". We also thank Worley Parsons Pty. Ltd. and the Governmental Department of Environment and Primary Industries, without which the resources for this project would have remained unattainable. We thank Gail Schofield, Gerry Quinn and Ty Matthews for constructive comments. Project development and analyses was conducted at Deakin University, Warrnambool, GIS Laboratory 
facility. We also thank the reviewers' for comments provided that aided with significant improvements on content and structure of the paper.

\section{Author Contributions}

Daniel Ierodiaconou, Jacquomo Monk, Alex Rattray and Richard Zavalas completed fieldwork surveys to acquire groundtruth data. David Ryan aided in processing of LiDAR datasets for the purpose of habitat mapping. Implementing classification algorithms and data analysis was conducted by Richard Zavalas, Jacquomo Monk and Alex Rattray. Daniel Ierodiaconou and Jacquomo Monk provided guidance on structure and content of results. Richard Zavalas wrote the manuscript with significant input on interpretation and arrangement from all the co-authors.

\section{Conflicts of Interest}

The authors declare no conflict of interest.

\section{References}

1. Jackson, J.B.C. Ecological extinction and evolution in the brave new ocean. Proc. Natl. Acad. Sci. USA 2008, 105, 11458-11465.

2. Crowder, L.; Norse, E. Essential ecological insights for marine ecosystem-based management and marine spatial planning. Mar. Policy 2008, 32, 772-778.

3. Diaz, R.J.; Solan, M.; Valente, R.M. A review of approaches for classifying benthic habitats and evaluating habitat quality. J. Environ. Manag. 2004, 73, 165-181.

4. Cogan, C.B.; Todd, B.J.; Lawton, P.; Noji, T.T. The role of marine habitat mapping in ecosystem-based management. Ices J. Mar.Sci. 2009, 66, 2033-2042.

5. Chust, G.; Grande, M.; Galparsoro, I.; Uriarte, A.; Borja, Á. Capabilities of the bathymetric hawk eye lidar for coastal habitat mapping: A case study within a basque estuary. Estuar. Coast. Shelf Sci. 2010, 89, 200-213.

6. Iampietro, P.J.; Kvitek, R.G.; Morris, E. Recent advances in automated genus-specific marine habitat mapping enabled by high-resolution multibeam bathymetry. Mar. Technol. Soc. J. 2005, 39, 83-93.

7. Cutter, G.R.; Rzhanov, Y.; Mayer, L.A. Automated segmentation of seafloor bathymetry from multibeam echosounder data using local fourier histogram texture features. J. Exp. Mar. Biol. Ecol. 2003, 285, 355-370.

8. Ierodiaconou, D.; Monk, J.; Rattray, A.; Laurenson, L.; Versace, V.L. Comparison of automated classification techniques for predicting benthic biological communities using hydroacoustics and video observations. Cont. Shelf Res. 2011, 31, 28-38.

9. Rattray, A.; Ierodiaconou, D.; Laurenson, L.; Burq, S.; Reston, M. Hydro-acoustic remote sensing of benthic biological communities on the shallow South East Australian continental shelf. Estuar. Coast. Shelf Sci. 2009, 84, 237-245.

10. Holmes, K.W.; van Niel, K.P.; Radford, B.; Kendrick, G.A.; Grove, S.L. Modelling distribution of marine benthos from hydroacoustics and underwater video. Cont. Shelf Res. 2008, 28, 1800-1810. 
11. Mather, P.M. Computer Processing of Remotely-Sensed Images-An Introduction, 3rd ed.; Wiley, J.,Chichester, S.,Eds.; Macsource Press: Oxford, UK, 2004.

12. Clarke, J.E.H.; Mayer, L.A.; Wells, D.E. Shallow-water imaging multibeam sonars: A new tool for investigating seafloor processes in the coastal zone and on the continental shelf. Mar. Geophys. Res. 1996, 18, 607-629.

13. Ryan, D.A.; Brooke, B.P.; Collins, L.B.; Kendrick, G.A.; Baxter, K.J.; Bickers, A.N.; Siwabessy, P.J.W.; Pattiaratchi, C.B. The influence of geomorphology and sedimentary processes on shallow-water benthic habitat distribution: Esperance Bay, Western Australia. Estuar. Coast. Shelf Sci. 2007, 72, 379-386.

14. Costa, B.M.; Battista, T.A.; Pittman, S.J. Comparative evaluation of airborne lidar and ship-based multibeam sonar bathymetry and intensity for mapping coral reef ecosystems. Remote Sens. Environ. 2009, 113, 1082-1100.

15. Irish, J.L.; Lillycrop, W.J. Scanning laser mapping of the coastal zone: The shoals system. ISPRS J. Photogramm. Remote Sens. 1999, 54, 123-129.

16. Vierling, K.T.; Vierling, L.A.; Gould, W.A.; Martinuzzi, S.; Clawges, R.M. Lidar: Shedding new light on habitat characterization and modeling. Front. Ecol. Environ. 2008, 6, 90-98.

17. Kuffner, I.B.; Brock, J.C.; Grober-Dunsmore, R.; Bonito, V.E.; Hickey, T.D.; Wright, C.W. Relationships between reef fish communities and remotely sensed rugosity measurements in Biscayne National Park, Florida, USA. Environ.Biol. Fishes 2007, 78, 71-82.

18. Wedding, L.M.; Friedlander, A.M.; McGranaghan, M.; Yost, R.S.; Monaco, M.E. Using bathymetric lidar to define nearshore benthic habitat complexity: Implications for management of reef fish assemblages in Hawaii. Remote Sens. Environ. 2008, 112, 4159-4165.

19. Wang, C.K.; Philpot, W.D. Using airborne bathymetric lidar to detect bottom type variation in shallow waters. Remote Sens. Environ. 2007, 106, 123-135.

20. Pittman, S.J.; Costa, B.M.; Battista, T.A. Using lidar bathymetry and boosted regression trees to predict the diversity and abundance of fish and corals. J. Coast. Res. 2009, 25, 27-38.

21. Walker, B.K.; Riegl, B.; Dodge, R.E. Mapping coral reef habitats in Southeast Florida using a combined technique approach. J. Coast. Res. 2008, 24, 1138-1150.

22. Lim, K.; Treitz, P.; Wulder, M.; St-Onge, B.; Flood, M. Lidar remote sensing of forest structure. Prog. Phys. Geogr. 2003, 27, 88-106.

23. Hill, R.A.; Thomson, A.G. Mapping woodland species composition and structure using airborne spectral and lidar data. Int. J. Remote Sens. 2005, 26, 3763-3779.

24. Toohey, B.D. The relationship between physical variables on topographically simple and complex reefs and algal assemblage structure beneath an ecklonia radiata canopy. Estuar. Coast. Shelf Sci. 2007, 71, 232-240.

25. Jones, C.G.; Lawton, J.H.; Mosche, S. Organisms as ecosystem engineers. Oikos 1994, 69, $372-386$.

26. Short, A.D. Sediment transport around australia-sources, mechanisms, rates, and barrier form. J. Coast. Res. 2010, 26, 395-402.

27. James, N.P.; Bone, Y.; von Der Borch, C.C.; Gostin, V.A. Modern carbonate and terrigenous clastic sediments on a cool water, high energy, mid-latitude shelf: Lacepede, southern Australia. Sedimentology 1992, 39, 877-903. 
28. Monk, J.; Ierodiaconou, D.; Bellgrove, A.; Laurenson, L. Using community-based monitoring with gis to create habitat maps for a marine protected area in australia. J. Mar. Biol. Assoc. UK 2008, 88, 865-871.

29. Rattray, A.; Ierodiaconou, D.; Monk, J.; Laurenson, L.; Kennedy, P. Quantification of spatial and thematic uncertainty in the application of underwater video for benthic habitat mapping. Mar. Geod. 2014, in press.

30. Ierodiaconou, D.; Burq, S.; Reston, M.; Laurenson, L. Marine benthic habitat mapping using multibeam data, georeferenced video and image classification techniques in Victoria, Australia. Spat. Sci. 2007, 52, 93-104.

31. Wernberg, T.; Goldberg, N. Short-term temporal dynamics of algal species in a subtidal kelp bed in relation to changes in environmental conditions and canopy biomass. Estuar. Coast. Shelf Sci. 2008, 76, 265-272.

32. McArthur, M.A.; Brooke, B.P.; Przeslawski, R.; Ryan, D.A.; Lucieer, V.L.; Nichol, S.; McCallum, A.W.; Mellin, C.; Cresswell, I.D.; Radke, L.C. On the use of abiotic surrogates to describe marine benthic biodiversity. Estuar. Coast. Shelf Sci. 2010, 88, 21-32.

33. Collin, A.; Long, B.; Archambault, P. Merging land-marine realms: Spatial patterns of seamless coastal habitats using a multispectral lidar. Remote Sens. Environ. 2012, 123, 390-399.

34. Jenness, J.S. Calculating landscape surface area from digital elevation models. Wildl. Soc. Bull. 2004, 32, 829-839.

35. Lundblad, E.R.; Wright, D.J.; Miller, J.; Larkin, E.M.; Rinehart, R.; Naar, D.F.; Donahue, B.T.; Anderson, S.M.; Battista, T. A benthic terrain classification scheme for american samoa. Mar. Geod. 2006, 29, 89-111.

36. Schmidt, J.; Evans, I.S.; Brinkmann, J. Comparison of polynomial models for land surface curvature calculation. Int. J. Geogr.Inf. Sci. 2003, 17, 797-814.

37. Delaney, J. Geographical Information Systems: An Introduction; Oxford University Press: Melbourne, Australia, 1999.

38. Wilson, M.F.J.; O’Connell, B.; Brown, C.; Guinan, J.C.; Grehan, A.J. Multiscale terrain analysis of multibeam bathymetry data for habitat mapping on the continental slope. Mar. Geod. 2007, 30, 3-35.

39. Daily, M. Hue-saturation-intensity split-spectrum processing of seasat radar imagery. Photogramm. Eng. Remote Sens. 1983, 49, 349-355.

40. Loh, W.Y.; Shih, Y.S. Split selection methods for classification trees. Statistica Sin. 1997, 7, 815-840.

41. Pal, M.; Mather, P.M. An Assessment of the effectiveness of decision tree methods for land Cover classification. Remote Sens. Environ. 2003, 86, 554-565.

42. Edwards, L. Catami Classification Scheme for Scoring Marine Biota and Substrata in Underwater Imagery. In CATAMI Classification Scheme for Scoring Marine Biota and Substrata in Underwater Imagery; iVEC: Kensington, Australia, 2013; pp. 1-17.

43. Franklin, J. Mapping Species Distributions-Spatial Inference and Prediction; Cambridge University Press: Cambridge, UK, 2009.

44. Congalton, R.G.; Green, K. Assessing the Accuracy of Remotely Sensed Date-Principles and Practices, 2nd ed.; CRC Press: New York, NY, USA, 2009. 
45. Jensen, J.R. Introductory Digital Image Processing, 3rd ed.; Pearson Prentice Hall: Upper Saddle River, NJ, USA, 2005.

46. Card, D.H. Using known map category marginal frequencies to improve estimates of thematic map accuracy. Photogramm. Eng. Remote Sens. 1982, 48, 431-439.

47. Ma, Z.K.; Redmond, R.L. Tau-coefficients for accuracy assessment of classification of remote-sensing data. Photogramm. Eng. Remote Sens. 1995, 61, 435-439.

48. Wang, C.K.; Philpot, W.; Kim, M.; Lei, H.M. A monte carlo study of the seagrass-induced depth bias in bathymetric lidar. Opt. Express 2011, 19, 7230-7243.

49. Brown, C.J.; Smith, S.J.; Lawton, P.; Anderson, J.T. Benthic habitat mapping: A review of progress towards improved understanding of the spatial ecology of the seafloor using acoustic techniques. Estuar.Coast. Shelf Sci. 2011, 92, 502-520.

50. Bruce, E.M.; Eliot, I.G.; Milton, D.J. Method for assessing the thematic and positional accuracy of seagrass mapping. Mar. Geod. 1997, 20, 175-193.

51. White, W.H.; Harborne, A.R.; Sotheran, I.S.; Walton, R.; Foster-Smith, R.L. Using an acoustic ground discrimination system to map coral reef benthic classes. Int. J. Remote Sens. 2003, 24, 2641-2660.

52. Wolter, P.T.; Johnston, C.A.; Niemi, G.J. Mapping submergent aquatic vegetation in the us great lakes using quickbird satellite data. Int. J. Remote Sens. 2005, 26, 5255-5274.

53. Kenny, A.J.; Cato, I.; Desprez, M.; Fader, G.; Schuttenhelm, R.T.E.; Side, J. An overview of seabed-mapping technologies in the context of marine habitat classification. Ices J. Mar. Sci. 2003, 60, 411-418.

54. Huff, L.C. Acoustic remote sensing as a tool for habitat mapping in Alaska waters. Mar. Habitat Mapp. Technol. Alsk. 2008, 10, 29-45.

55. Copeland, A.; Edinger, E.; Devillers, R.; Bell, T.; LeBlanc, P.; Wroblewski, J. Marine habitat mapping in support of marine protected area management in a subarctic fjord: Gilbert Bay, Labrador, Canada. J. Coast. Conserv.2013, 17, 225-237.

56. Legendre, P. Spatial autocorrelation-trouble or new paradigm. Ecology 1993, 74, 1659-1673.

57. Foster, S.D.; Bravington, M.V.; Williams, A.; Althaus, F.; Laslett, G.M.; Kloser, R.J. Analysis and prediction of faunal distributions from video and multi-beam sonar data using Markov models. Environmetrics 2009, 20, 541-560.

58. Ferrier, S.; Watson, G.; Pearce, J.; Drielsma, M. Extended statistical approaches to modelling spatial pattern in biodiversity in Northeast New South Wales. I. Species-level modelling. Biodivers. Conserv. 2002, 11, 2275-2307.

59. Collin, A.; Archambault, P.; Long, B. Mapping the shallow water seabed habitat with the shoals. IEEE Trans.Geosci. Remote Sens. 2008, 46, 2947-2955.

60. Tulldahl, H.M.; Wikström, S.A. Classification of aquatic macrovegetation and substrates with airborne lidar. Remote Sens. Environ. 2012, 121, 347-357.

61. Collin, A.; Archambault, P.; Long, B. Predicting species diversity of benthic communities within turbid nearshore using full-waveform bathymetric Lidar and machine learners. PLoS One 2011, 6, doi:10.1371/journal.pone.0021265.

62. Tulldahl, H.M.; Philipson, P.; Kautsky, H.; Wikstrom, S.A. Sea floor classification with satellite data and airborne lidar bathymetry. Proc. SPIE 2013, doi:10.1117/12.2015727. 
63. Valle, M.; Borja, A.; Chust, G.; Galparsoro, I.; Garmendia, J.M. Modelling suitable estuarine habitats for Zostera noltii, using ecological Niche Factor analysis and Bathymetric LiDAR. Estuar. Coast. Shelf Sci. 2011, 94, 144-154.

64. Hladik, C.; Schalles, J.; Alber, M. Salt marsh elevation and habitat mapping using hyperspectral and lidar data. Remote Sens. Environ. 2013, 139, 318-330.

65. Irving, A.D.; Connell, S.D. Interactive effects of sedimentation and microtopography on the abundance of subtidal turf-forming algae. Phycologia 2002, 41, 517-522.

(C) 2014 by the authors; licensee MDPI, Basel, Switzerland. This article is an open access article distributed under the terms and conditions of the Creative Commons Attribution license (http://creativecommons.org/licenses/by/3.0/). 